\title{
Health action with elderly communities of high vulnerability in Belo Horizonte: relevance and results
}

\begin{abstract}
Background: The knowledge of the epidemiological profile of the elderly population in areas of high socioeconomic vulnerability is essential for the diagnosis and the efficacy of care.

Objective: This article aims to identify priorities for future interventions in small communities through one day evaluation of several measures of the elderly, such as blood pressure, capillary glycemia, Mini Mental State Examination (MMSE), calf circumference and "get up and go" test, to obtain these patients" risk of falling. From this, we intend to suggest a method that could be used in future similar events.
\end{abstract}

Method: A cross-sectional evaluation was performed at FEMAM with the population over 65 years. The following variables were measured: age, vaccination status, smoking, alcoholism, height, body mass index (BMI), blood pressure, waist circumference, calf circumference, and the "get up and go" test.

Results: 46 elderly people took part in the activity. The mean value of systolic BP was $141.5 \pm 22.4 \mathrm{mmHg}$. The mean BMI and abdominal circumferences were $27.1 \pm 4.4 \mathrm{~kg} /$ $\mathrm{m}^{2}$ and $93 \pm 11 \mathrm{~cm}$, respectively. 18 patients were smokers or former smokers $(39.1 \%)$ and alcohol abuse was reported in 16 patients $(37.2 \%)$. The average time in the "get up and go" test was $14.1 \pm 4.3$ seconds.

Conclusion: This intervention has been considered an efficient method to determine the prevalence of risk factors for falling and cardiovascular outcomes. Thus, with the accomplishment of this joint effort, it was possible to get a better knowledge of the elderly of the community and their comorbidities. The results suggest that it is still necessary to carry out similar actions with a larger sample of elderly to validate our findings.

Keywords: public health surveillance, elderly, cardiovascular risk, accidental falls, social vulnerability areas
Volume 4 Issue 5 - 2019

\author{
Thales Pardini Fagundes,' Carolina Belfort \\ Resende Fonseca,' Isabela Safar Paim,' \\ Larissa Amora Gomes,' Letícia Utsch \\ Araujo,' Maria Isabel Menezes Guedes,' \\ Matheus Coelho Rocha,' Matheus Lucas \\ Vasconcelos Miranda,' Monisi Peres Lopes,' \\ Otávio Vitório Alvarenga Pereira,' Rafael \\ Nogueira Gingold,' João Márcio Gomes de \\ Faria, ${ }^{2}$ Pedro Henrique Diniz Cunha, ${ }^{3}$ Luís \\ Felipe José Ravic de Miranda ${ }^{4}$ \\ 'Medical student, Federal University of Minas Gerais, Brazil \\ ${ }^{2}$ Local Physician, Federal University of Minas Gerais, Brazil \\ ${ }^{3}$ Psychiatry Resident, Federal University of Minas Gerais, Brazil \\ ${ }^{4}$ Department of Clinical Medicine, Federal University of Minas \\ Gerais, Brazil
}

Correspondence: Luís Felipe José Ravic de Miranda, MD, PhD Department of Clinical Medicine, Federal University of Minas Gerais, Brazil, Tel +553 | 984599393 , Email ravicmiranda@gmail.com

Received: September 26, 2019 | Published: October II, 2019
Abbreviations: UFMG, Federal University of Minas Gerais; MMSE, mini mental state examination; FEMAM, mining-influenced surrounding area entity forum, BMI, body mass index; BP, blood pressure; SBP, systolic blood pressure; DBP, diastolic blood pressure

\section{Introduction}

An effective follow-up in primary health care services could prevent diseases, enhance autonomy and increase the adherence to treatment. In elderly people it could improve the quality of life, reducing morbidity and mortality. Cardiovascular diseases still play a prominent role in mortality in the population aged 65 and over ${ }^{[1]}$. In addition, fractures, which involves a physical disability, loss of mobility and other disorders, make the assessment of the risk of falls another important factor to be tested in the consultations. Taking these facts into consideration, the authors have observed the importance of knowing the epidemiological profile of the elderly and, on the $1^{\text {st }}$ September of 2018, they made the first collective assessment at "Vila Acaba Mundo," a region of high social vulnerability in the southern area of Belo Horizonte, Brazil. The activity included a multiprofessional team composed of medical students, doctors, nurses, social workers and nutritionists.

The event was held at the Mining-Influenced Surrounding Area Entity Forum (FEMAM). Patients were assessed by medical students from the Federal University of Minas Gerais (UFMG), supervised by physicians from the Department of Internal Medicine (DCLM) of the same Institution, in an outpatient clinic with free attendance on Saturdays. This project is called: Taking care of your health in "Vila Acaba Mundo" and was created in December 2016. The project also involves other voluntary activities, such as outpatient consults in an area of vulnerability at the north of Minas Gerais. This article aims to identify the priorities for a collective intervention of the patients treated, focusing on modifiable cardiovascular risk factors, and to suggest a method, e.g. a questionnaire, that can be applied for a fast identification of the main risks for an elderly subpopulation.

\section{Material and methods}

We conducted a cross-sectional assessment, lasting five hours. The population tested was composed by elderly over 65 years who live in "Vila Acaba Mundo". They were invited to take part and came for spontaneous demand. The following variables were obtained: age, vaccination status, smoking, and alcoholism. Anthropometric measures such as: weight, height, body mass index (BMI), abdominal circumference and calf circumference were also assessed. The ethics committee of the Federal University of Minas Gerais authorized this research, and the elderly signed a consent form allowing the interview. The research project was approved by the Research Ethics Committee of "Plataforma Brasil" under number 76768417.5.0000.5149. The data were collected in a day on the $1^{\text {st }}$ of September 2018 by medical students of the fourth year or more supervised by a local physician and a professor at UFMG. We performed a brief physical examination 
to get several data: random capillary blood glucose (without knowing fasting status), blood pressure (supine and standing position). Orthostatic hypotension was defined as a decrease greater than 20 $\mathrm{mmHg}$ in systolic pressure or greater than $10 \mathrm{mmHg}$ in diastolic pressure $^{1-3}$ In addition, the risk of falling was investigated by the "get up and go test". Values above 13.5 seconds were considered altered for the elderly. ${ }^{4}$ The reference value adopted for waist circumference was $88 \mathrm{~cm}$ for women and $102 \mathrm{~cm}$ for men. ${ }^{5-7}$ For the "get-up and go test", 9.2 seconds were used, based on age-dependent values. ${ }^{8}$ Patients who had systolic pressure values higher than $180 \mathrm{mmHg}$ without clinical signs of target organ injury were classified as "hypertensive urgency". 9 All tests were performed in R (Version 2.14.2; http://www.r-project. org/) and RStudio (Version 0.97; http://www.rstudio.com).

\section{Results}

Table 1 outlines the essential characteristics of the community. We attended 46 subjects with a mean age of 70 years. According to Table 2: five patients $(10.9 \%)$ showed a decrease in systolic blood pressure $>20 \mathrm{mmHg}$ when comparing the orthostatic with the supine position after $3 \mathrm{~min}$. Regarding blood pressure levels, 30 elderly (65.2\%) had SBP higher than $130 \mathrm{mmHg}, 4$ had DBP greater than 90 $\mathrm{mmHg}$, and 3 patients had SBP>180 $\mathrm{mmHg}$ (Table 2), values above the sets accepted by American Heart Association, published in 2017. Among the participants, 18 are smokers or former smokers (39\%), and 16 described ongoing or past consumption of ethanol (37\%). $71.4 \%$ of patients had capillary blood glucose above $100 \mathrm{mg} / \mathrm{dL}$ (Table 2).

Table I Patients characteristics $(n=46)$

\begin{tabular}{lccll}
\hline Variable & $\mathbf{n ~ I}$ & $\mathbf{( \% )}$ & Mean & $\begin{array}{l}\text { Standard } \\
\text { deviation (sd) }\end{array}$ \\
\hline Age & 45 & $97.83 \%$ & 70.56 & 7.78 \\
$\begin{array}{l}\text { Systolic Blood Pressure } \\
(\mathrm{mmHg})\end{array}$ & 46 & $100.00 \%$ & 141.48 & 22.37 \\
Get up and Go (seconds) & 44 & $95.65 \%$ & 14.11 & 4.34 \\
$\begin{array}{l}\text { Waist circumference }(\mathrm{cm}) \\
\text { Calf circumference }(\mathrm{cm})\end{array}$ & 33 & $71.74 \%$ & 93.06 & 11.02 \\
\begin{tabular}{l} 
Body Mass Index $\left(\mathrm{kg} / \mathrm{m}^{2}\right)$ \\
\hline
\end{tabular} & 33 & $71.74 \%$ & 27.11 & 4.48 \\
\hline
\end{tabular}

Table 2 Patients with higher blood pressure and orthostatic hypotension. (Total of patients=46)

\begin{tabular}{ll}
\hline Parameters & Result (\%) \\
\hline Total of patients with high blood pressure & $32(69.56)$ \\
$(>130 \times 80 \mathrm{mmHg})$ & \\
Only systolic blood Pressure $>$ I $30 \mathrm{mmHg}$ & $15(32.60)$ \\
Systolic blood pressure $>$ I $80 \mathrm{mmHg}$ & $3(6.52)$ \\
Systolic blood pressure variation $>20 \mathrm{mmHg}$ & $5(10.8)$ \\
Smoking & $18(39.13 \%)$ \\
Alcohol use & $16(37.21 \%)$ \\
Random capillary blood glucose, in $\mathrm{mg} / \mathrm{dL}$ & 22 values obtained (47.82\%) \\
$>$ I00 & $15(71.42 \%)$ \\
$>$ I 26 & $7(33.33 \%)$ \\
Maximum Value & 175 \\
\hline
\end{tabular}

\section{Discussion}

The authors observed a high prevalence of blood pressure values $(69.6 \%)$, mainly systolic. The prevalence of hypertensive urgency was $6.5 \%$. The mean values of waist circumference and BMI are 93 $\mathrm{cm}$ and $27 \mathrm{~kg} / \mathrm{m}^{2}$, respectively. Current or history of smoking and alcohol was present in almost $40 \%$ of patients. Finally, capillary blood glucose was higher than $100 \mathrm{mg} / \mathrm{dL}$ in $71.4 \%$ of participants. The parameters investigated are directly associated to cardiovascular risk assessment, besides other morbidities.

We found an elevation in systolic blood pressure in $32.6 \%$ of the patients. Systolic blood pressure was above $180 \mathrm{mmHg}$ in 3 patients $(6.5 \%)$, representing hypertensive urgency. The average BMI was over $27 \mathrm{~kg} / \mathrm{m}^{2}$. The importance of identifying overweight and obesity, the present consumption of tobacco and alcohol are intimately associated with fatal cardiovascular events. Additionally, evidence shows that elevated BMI is an independent risk factor for global mortality, including the elderly. ${ }^{10,11}$

Therefore, these results show the need to promote other similar experiences to evaluate some parameters and increase the quality of life, the self-recognition of certain diseases and the risk to acquire health problems. When patients know their health status and the specific meaning of these measures cited above (such as blood pressure, capillary glycemia, Mini Mental State Examination (MMSE), calf circumference and "get up and go" test), they become more aware of their self-care. Several cases of orthostatic hypotension and measures above than 13.5 seconds at "get-up and go test" were observed, both associated with a higher risk of falling. ${ }^{12,13}$

A systematic meta-analysis review which included 10 studies, showed good test specificity, although it was poorly sensitive. ${ }^{4}$ Moreover, in this study, this test was not a good predictor of falls.

This type of practice should be strengthened and systematized based on evidence. This study highlights the performance of the task force, since it is not expensive and brings up some important data for the knowledge of patients, enabling them to take longitudinal care of their health.

This study has some limitations. We performed measurements at a single moment, which may impair the reliability of the data. Study members were trained to standardize and measure data to avoid measurement bias. It is possible that the population attending the event is not representative of the community, as many frail seniors cannot attend the event. It is essential to associate this cross evaluation with longitudinal care and home visits. Examples of analogous interventions occurred in the University of the São Paulo Medical School, ${ }^{14}$ in the city of Miraselva and Guaratuba.

\section{Conclusion}

The practice of evaluation of health by punctual actions is common in Brazil and strengthens the bonds between health professionals, students and the community. ${ }^{15}$ Moreover, it allows to make diagnostic hypothesis and encourages people to follow-up with a doctor. This joint effort becomes efficient when combined with a proper follow-up and continued care, otherwise, it may not impact the morbidity and mortality. ${ }^{14,16}$ Some community's residents rarely attend to medical assignments. However, they take part in massive-scale events, which increases its effectiveness.

\section{Acknowledgments}

Taís Kelly Silva, she is the Secretary and responsible for scheduling appointments. 


\section{Conflicts of interests}

Authors declare that there is no conflict of interest

\section{References}

1. Gorina Y, Lentzner H. Multiple causes of death in old age. Aging Trends. 2008;(9):1-9.

2. Kanjwal K, George A, Figueredo VM, et al. Orthostatic hypotension: definition, diagnosis and management. J Cardiovasc Med. 2015;16(2):7581 .

3. Schatz IJ, Bannister R, Freeman RL, et al. Consensus statement on the definition of orthostatic hypotension, pure autonomic failure and multiple system atrophy. In: Clinical Autonomic Research. 1996;46(5).

4. Barry E, Galvin R, Keogh C, et al. Is the Timed Up and Go test a useful predictor of risk of falls in community dwelling older adults: A systematic review and meta- analysis. BMC Geriatr. 2014;14:14.

5. Janssen I, Katzmarzyk PT, Ross R. Body mass index, waist circumference, and health risk. Arch Intern Med. 2002; 162(18):2074-2079.

6. Han TS, Van Leer EM, Seidell JC, et al. Waist circumference action levels in the identification of cardiovascular risk factors: Prevalence study in a random sample. BMJ. 1995;311(7017):1401-1405.

7. de Hollander EL, Bemelmans WJ, Boshuizen HC, et al. The association between waist circumference and risk of mortality considering body mass index in 65- to 74-year-olds: A meta-analysis of 29 cohorts involving more than 58000 elderly persons. Int J Epidemiol. 2012;41(3):805-817.

8. Bohannon RW. Reference values for the timed up and go test: A descriptive meta-analysis. J Geriatr Phys Ther. 2006; 29(2):64-68.
9. Malachias MVB, Souza WKSB, Plavnik FL, et al. 7a Diretriz brasileira de hipertensão arterial. Arq Bras Cardiol. 2016;107(3):3.

10. Kalmijn S, Curb JD, Rodriguez BL, et al. The association of body weight and anthropometry with mortality in elderly men: The Honolulu Heart Program. Int J Obes. 1999;23(4):395-402.

11. Grzegorzewska A, Wołejko K, Kowalkowska A, Kowalczyk G, Jaroch A. Proper BMI ranges for the elderly in the context of morbidity, mortality and functional status. Gerontol Pol. 2016;24:114-148.

12. Feder G, Cryer C, Donovan S. Review: Falls can be prevented in older people, but interventions should be multifaceted and targeted. Evid Based Med. 2001; 321(7267):1007-1011.

13. Schoene D, Wu SMS, Mikolaizak AS, et al. Discriminative ability and predictive validity of the timed up and go test in identifying older people who fall: Systematic review and meta-analysis. J Am Geriatr Soc. 2013;61(2):202-208.

14. Monaco T de O, Filho WJ. A health campaign for the elderly: developing a health promotion strategy for the elderly using functional assessments of community dwelling individuals. Einstein. 2007;5:1-5.

15. Cardoso CL. "Health work" as an interdisciplinary action of primary health care Learn to pronounce. Gerais Rev Interinstitucional Psicol. 2015;8:177-93.

16. Ministry of Health. Secretariat of health care. Department of primary care. Primary care notebooks, n. 29 - Tracking. Cad Primary care tracking. Brazil; 2010. 